\title{
APLIKASI PRODUK BOARD GAME 'HOOTANIA' SEBAGAI UPAYA MENINGKATKAN MINAT BACA PADA ANAK
}

\author{
Tiphanny Aurumajeda ${ }^{1}$, Martiyadi Nurhidayat ${ }^{2}$ \\ Program Studi Desain Komunikasi Visual ${ }^{1}$, Program Studi Desain Produk ${ }^{2}$ \\ Sekolah Tinggi Teknologi Bandung ${ }^{1}$ \\ Telkom University ${ }^{2}$ \\ tiphannyaurumajeda@gmail.com ${ }^{1}$, martiyadi@telkomuniversity.ac.id ${ }^{2}$
}

\begin{abstract}
Abstrak
Membaca adalah dasar dari ilmu yang perlu kita perhatikan banyaknya program dari Lembaga pemerintahan tentang budaya literasi di sekolah ataupun di masyarakat, akan tetapi yang perlu diperhatikan adalah masih sangat kurang budaya membaca. Efektifitas penerapan dalam kebiasaan budaya membaca adalah sejak dini yang di terapkan oleh orang tua dan guru. Penelitian ini menggunakan metode kualitatif dengan pendekatan studi kasus dan pencarian data dengan teknik user center designed dengan tahapan alur analisis, desain, evaluasi dan implementasi . Maka hasil yang diberikan berupa project base produk boardgame 'Hootania' yang memiliki indicator ketercapaian mampu membaca, mengenal hewan, mengenal warna, dan berhitung disudut visualisasi produk ini mengkedapankan pendekatan user pada umur 4 hingga 6 tahun. Luaran hasil produk mampu mengatasi permasalahan pengenalan membaca kepada peserta didik.
\end{abstract}

Kata Kunci: Boardgame, Membaca, Anak

\begin{abstract}
Reading is a basic science that we need to pay attention to. There are many programs from government agencies about literacy culture in schools and in the community, but what needs to be considered is the lack of reading culture. The effectiveness of the application of a reading culture that is applied from an early age by parents and teachers. This research uses a qualitative method with a case study approach and data collection using a technique designed by the user center with the stages of flow analysis, design, evaluation and implementation. Then the results given are in the form of a project base for the 'Hootania' boardgame product which has achievement indicators of being able to read, recognize animals, recognize colors, and count in the visualization angle of this product, prioritizing the approach of users aged 4 to 6 years. The product output is able to overcome the problem of reading recognition in students.
\end{abstract}

Keywords: Boardgame, Reading, Children

\section{PENDAHULUAN}

Pengetahun didapat dikarenakan rajin membaca dan bertanya baik dari media cetak maupun elektronik, membaca diajarkan sejak dini penerapan dalam disiplin ilmu Pendidikan pergeseran kurikulum terjadi guna merubah pola pikir dan tingkah laku dalam budaya membaca.Rendahnya minat membaca masyarakat, erat hubungannya dengan tingkat pendidikan di negara tersebut [5]. Menurut peraturan Undang- Undang Republik Indonesia Nomor 43 Tahun 2007 tentang perpustakaan bahwa budaya kegemaran membaca dilakukan melalui keluarga, satuan pendidikan, dan masyarakat dengan kerjasama antara pemerintah dalam upaya peningkatan minat baca, dimana pemerintah bertindak sebagai pihak yang bertanggung jawab utama dan pustakawan melakukan kinerja yang optimal (www.perpusnas.go.id).

Pendidikan dikeluarga adalah hal yang utama dalam mengajarkan budaya membaca, beretika, dan lainnya. Peran orang tua adalah hal yang utama dalam mendukung rancangan kurikulum sekolah baik itu formal maupun informal. Kegiatan belajar mengajar sebagai upaya meningkatkan Pendidikan dalam kecerdasan dan kebiasaan yang berwawasan karakter dan beretika. Kurikulum dalam upaya meningkatkan udaya membaca di terapkan dari sejak dini yaitu Taman Kanak-kanak. Capaian Pembelajaran dalam indicator membaca di Taman Kanak kanak merupakan kewajiban untuk peserta didik jika akan melanjutkan ke tingkat berikutnya, sehingga belajar membaca ini dirasa sangat penting bagi siswa tingkat TK.

Pada saat ini sesungguhnya para siswa dihadapkan pada pada persoalan bagaimana mengatasi keterbatasan waktu dan dapat membaca dalam waktu yang relatif singkat tetapi dapat memperoleh informasi yang sebanyak-banyaknya [8]. Upaya penerapan perlu adanya Kerjasama di sekolah ataupun dirumah. Selain itu pengajar menerapkan mampu menerapkan metode pembelajaran yang menyenangkan guna meningkatkan mutu budaya membaca yang masih dirasa kurang bervariasi dalam kegiatan belajar mengajar, sehingga capaian pembelajaran tidak tercapai. Kurangnya wawasan metode pembelajaran dan sarana prasarana pendukung untuk kegiatan belajar menjadi alasan utama pengajar dalam menerapkan upaya kegiatan membaca.

Metode pembelajaran yang beragam mengacu pada kreatifitas pengajar sehingga upaya membaca tersebut memiliki banyak prograp sekolah yang diterapkan, seperti membuat bord game yang mengupayakan peserta didik membaca pesan atau 
informasi dari permainan tersebut. Aplikasi peracangan board game dalam penerapanya akan mengefektifkan waktu dalam mengajarkan membaca karena bord game dapat membawa peserta didik lebih tenang dan menyenangkan maka ketercapaian membaca dalam konteks minat membaca akan menjadi budaya.

\section{TINJAUAN PUSTAKA}

\section{Membaca}

Pergeseran budaya menjadi urgenitas yang harus diperbaiki seperti budaya membaca adalah upaya peningkatan mutu Pendidikan agar masyarakat Indonesia dapat memiliki mutu Pendidikan yang baik . Pemerintah telah mencanangkan program Gerakan Literasi Bangsa (GLB) yang bertujuan untuk menumbuhkan budi pekerti anak melalui budaya literasi [1]. Jika anak bangsa telat dalam membaca ini menjadi tugas penting bagi keluarga khususnya orang tua dan pengajar.

Budaya literasi perlu adanya pembiasaan dan kesadaran di lingkungan masyarakat. Para orang tua seharusnya mampu membimbing anak-anaknya sejak dini untuk gemar membaca. Usia anak dini merupakan usia emas yang mana masa tersebut merupakan masa para anak memiliki ingatan panjang. Usia dini adalah kesempatan emas anak dalam mempelajari sesuatu atau dapat disebut dengan golden age [9]. Di Negara maju seperti Jepang, gerakan membaca telah dirintis sejak 30 tahun lalu. Jepangmemberlakukan gerakan membaca 20 menit untuk ibu dan anak.Dalam gerakan ini seorang ibu dianjurkan membacakan buku 20 menit untuk anaknya yang bisa dipinjam dariperpustakaan umum.Tak diragukan lagi, kemajuan yang dicapai Jepang pada saat ini merupakan buah dari kerja keras pemerintah Jepang untuk membangun budaya literasi yang dimulai sejak dari anak- anak [10].

Perlu diperhatikan bahwa budaya baca adalah pembiasaan yang harus dieterapkan dalam ruang lingkup terkecil seperti keluarga maka orang tua dapat membiasakan setiap harinya untuk membaca, kualitas Pendidikan diajarkan di sekolah dari jenjang PAUD, Tk, SD hingga perguruan Tinggi membaca menjadi dasar yang diharuskan. Belajar membaca diterapkan di TK yang didukung dan diajarkan Kembali oleh orang tua, kerja sama ini untuk memperlihatkan output kebiasaan yang dilakukan terus menerus oleh anak.

Banyaknya metode dalam meningkatkan upaya membaca diantaranya dengan cara membuat permainan seperti hal nya board game, yang mana dalam permainan tersebut ada informasi yang harus dibacakan oleh peserta didik untuk dapat menjalankan permainan tersebut. Aplikasi dalam board game ini adalah sebagai media pembelajaran. Model pembelajaran dengan menggunakan media seni rupa bertujuan agar anak dapat dan mampu menciptakan sesuatu berdasarkan hasil imajinasinya, mengembangkan kepekaan dan dapat menghargai hasil karya yang kreatif [7].

\section{Perancangan media pemelajaran}

Semua anak senang bermain, setiap anak menyukai permainan karena melalui bermain anak belajar untuk memahami lingkungan sekitar.[4]. Belajar sambil bermain merupakan aplikasi metode yang mengajak peserta didik belajar dengan sebuah permainan, dimana permainan tersebut memiliki nilai dalam mendidik. Metode tersebut akan tercapai jika adanya media pembelajaran, hal ini akan menymakan persepsi siswa satu dengan lainnya.

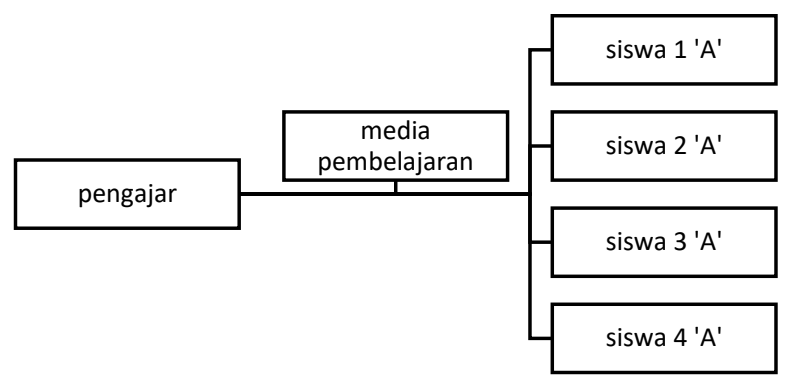

Gambar 1. Proses Komunikasi Yang Berhasil

Sumber : [12]

Penggunaan media pembelajaran dalam dunia pendidikan bertujuan untuk menciptakan pembelajaran yang menyenangkan [6].dalam kegiatan belajar mengajar menyenangkan adalah kunci untuk ilmu dapat menyerap dengan sempurna sehingga dengan adanya media ini akan sangat membantu untuk dapat menghafal, dan mengaplikasikannya. Fungsi media pendidikan adalah menciptakan interaksi langsung dan tak langsung antara sumber pesan, guru, media dan siswa untuk membantu mengatasi berbagai hambatan-hambatan dalam proses belajar mengajar, sehingga proses komunikasi akan berhasil [2]. 
3. Visualisasi perancangan

Media Pendidikan memiliki tiga jenis yaitu audio, visual, dan audio visual, ke tiga jeis tersebut yang akan merangsan panca indra. Media yang diaplikasikan pada penelitian ini adalah medi visual tidak bergerak yaitu berupa gameboard yang Bernama 'hootania'. Adapun indicator ketercapaian dalam visualisasi adalah

TABEL I

UNSUR DAN PRINSIP TATA DESAIN

\begin{tabular}{|c|c|}
\hline \multicolumn{2}{|c|}{ Sumber : [11] } \\
\hline Unsur seni & Prinsip seni \\
\hline Titik & Keseimbangan \\
\hline garis & Harmoni \\
\hline Bidang & Pola \\
\hline Bentuk & Penekanan \\
\hline Warna & \\
\hline Tekstur & \\
\hline Gelap dan terang & \\
\hline
\end{tabular}

\section{ANALISIS DAN PERANCANGAN}

Metode penelitian yang digunakan adalah metode kualitatif, menurut metode kualitatif secara potensial dapat berguna dalam menyumbangkan pembangunan teori-teori ilmu sosial serta metodologi[3]. Penelitian ini menggunakan pendekatan studi kasus dengan user design center sebagai alat pencarian datanya. Dapat dikatakan penelitian ini melihat permasalahan dilingkungan dengan konsep mngkedapankan kebutuhan objek penelitian untuk menjadikan sumber perancangan media boardgame yang sesuai dengan kebutuhan user.
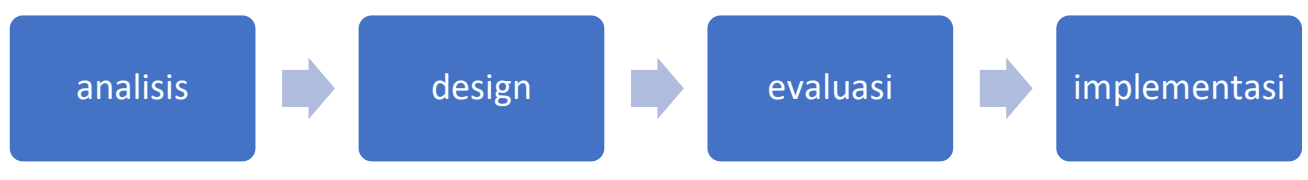

Gambar 2. Alur Pendekatan User Design Centered

\section{Analisis Data}

Data awal perancangan dalam pendekatan kepada user sebagai embrio dalam proses perancangan board game yaitu dari 50 responden anak taman kanak kanak dari umur 4 hingga 6 tahun dan pengajar 20 responden dengan umur antara 25 hingga 55 tahun

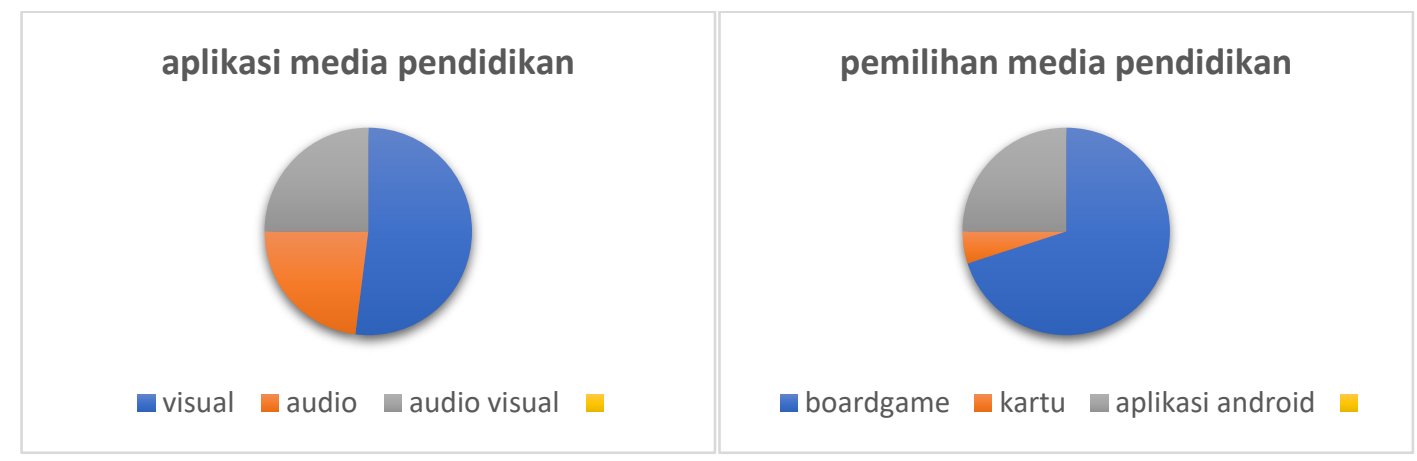

Gambar 3. Hasil Data Pencaharian Sebagai Awal Dalam Perancangan Boardgame Sumber: Penulis. 2021

Dilihat dari persentasi diatas memperlihaaaatkan dari 70 responden yang memilih visual sebanyak $52 \%$ dan yang memilih game board sebanyak 70\%. Pencarian data tersebut dibantu oleh kuesioner dengan memperluhatkan pemilihan 
gambar contoh yang mengarah kepada indicator pertanyaan. Data tersebut di pengaruhi oleh kondisi sarana prasarana sekolah, kemampuan pengajar, dan kemampuan peserta didik.

\section{Desain Bordgame}

Dalam perancangan boardgame ini melihat dari pencarian data yang sudah dianalisis sehingga memiliki gambaran dalam perancangannya. Adapun perancangan tersebut dilakukan yang pertama dibuatnya sketsa dilanjutkan membuat prototype.

TABEL II

TAHAPAN SKETSA DAN UNSUR DALAM BOARGAME

\begin{tabular}{|c|c|c|}
\hline Tahapan & Gambar & Penjelasan \\
\hline Sketsa & & $\begin{array}{l}\text { Pembuatan sketsa berguna } \\
\text { meminimalisir kesalahan dalam proses } \\
\text { produksi, mngatur perencanaan dasar sebuah } \\
\text { desain. }\end{array}$ \\
\hline Prototype & & $\begin{array}{l}\text { Track ini dibentuk menyerupai huruf } \mathrm{H} \text { yang } \\
\text { merupakan huruf depan dari nama permainan } \\
\text { ini. Track nya terdapat } 30 \text { kotak dengan setiap } \\
\text { kotaknya di isi dengan warna primer dan di } \\
\text { tambah dengan bentuk visual berupa hewan } \\
\text { dan juga benda Setiap kotaknya memiliki } \\
\text { warna yang berbeda-beda, dan warna yang di } \\
\text { pilih warna primer karena memiliki warna } \\
\text { yang cukup cerah }\end{array}$ \\
\hline & $10 \mathrm{~cm}$ & $\begin{array}{l}\text { Permainan Board Game ini terdapat } \\
\text { tiga buah pion dengan karakter satu orang anak } \\
\text { laki-laki, satu orang anak perempuan, dan } \\
\text { seekor monyet. } \\
\text { seorang anak laki-laki dengan memakai } \\
\text { topi dan rompi warna coklat, dengan celana } \\
\text { berwarna hijau dan membawa tas. Karakter ini } \\
\text { memvisualisasikan seolah-olah anak laki-laki } \\
\text { tersebut sedang berpetualang. } \\
\text { seoarang anak perempuan dengan } \\
\text { memakai topi berwarna merah mudah, } \\
\text { menggondong tas merah muda juga dan } \\
\text { menggunakan rompi berwarna coklat } \\
\text { penggunaan warna merah muda pada topi dan } \\
\text { juga tas adalah untuk menunjukan sisi feminim } \\
\text { dari karakter Nia }\end{array}$ \\
\hline
\end{tabular}




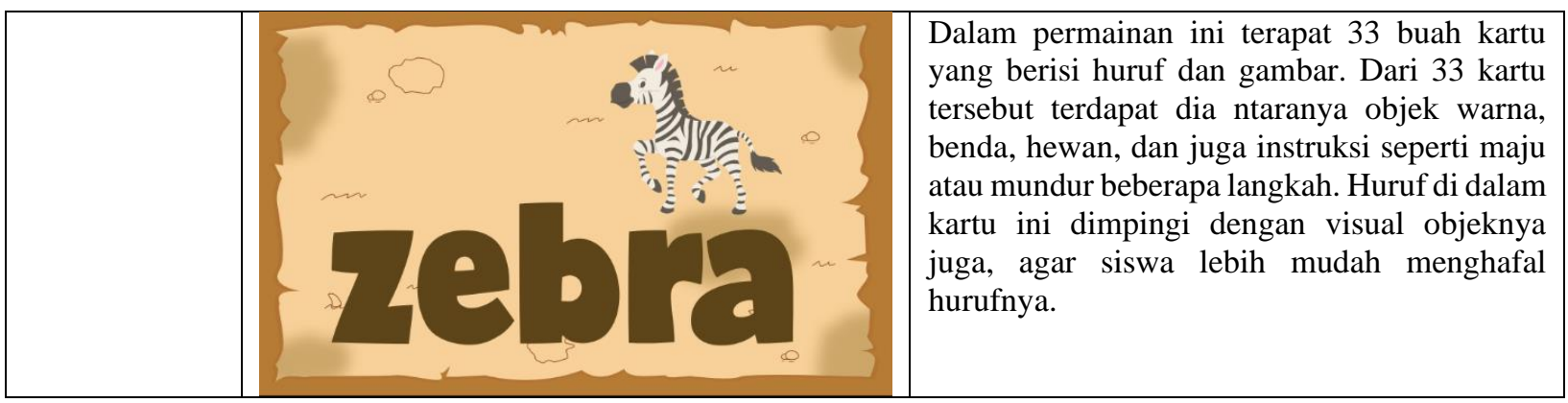

3. Evaluasi

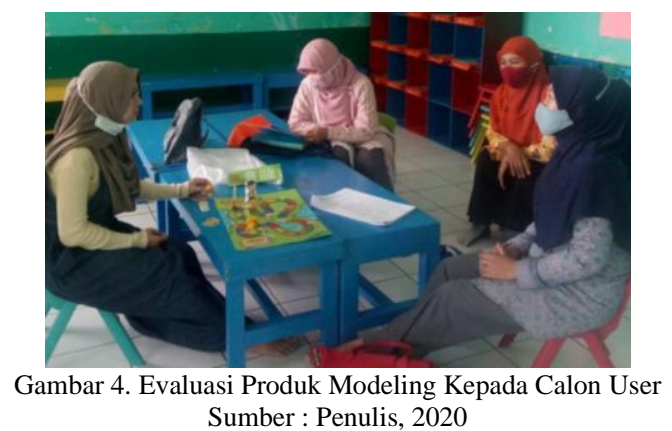

Melakukan evaluasi dari modeling boargame sebelum pengenalan kebeberapa ikatan guru taman kanak kanak dan orang tua siswa penulis melakukan evaluasi dengan berdiskusi dan bertanya kecocokan permasalahaan dengan solusi yang diberikan Adapun yang kriteria pembelajaran yang ada didalam boardgame sebagai berikut:

a. Peserta didik mampu membaca perkata dalam kartu yang disajikan

b. Peserta didik mampu membacakan jenis hewan, dan warna.

c. Peserta didik mampu menghitung dalam menjalankan permainannya.

d. Peserta didik mampu mengenali hewan dan huruf yang tertera dalam kartu dan boardgame baik bersifat gambar atau tulisan

Hal ini berguna untuk mencari kesalahan dan kekurangan dari modeling tersebut dengan bertanya dan mengevaluasi kepada calon user yaitu pengajar taman kanak kanak di daerah Bandung Barat. Evaluasi ini dapat diperharikan adalah permasalahan bentuk, warna, alur bermain, keterbacaan, huruf dan lain lain agar dapat lebih sempurna baik dari visual, alur bermain atau dari ergonomic produk.

\section{Implementasi}

Produk boardgame hootania melakukan pengenalan kepada pihak pihak yang terkait seperti pengajar, kepala sekolah, pengurus ikatan guru taman kanak kanak dan orant tua siswa dalam hal ini produk disebar dan diuji cobakan kepada anak usis 4 hingga 6 tahun pada tingkat taman kanak kanak yang dilakukan maksimal 3 orang pemain dalam satu boargame.

TABEL III

PARAMETER HASIL SURVEY APLIKASI DALAM MEMBACA ANAK PADA USIA 4 HINGGA 6 TAHUN Sumber: Penulis, 2021

\begin{tabular}{|c|c|c|}
\hline Indikator ketercapaian & Nilai (1-5) & Keterangan \\
\hline Keterampilan membaca perkata & 4 & Baik \\
\hline Keterampilan mengenal hewan & 5 & Sangat baik \\
\hline Keterampilan mengenal warna & 5 & Sangat baik \\
\hline Keterampilan menghitung & 4 & Baik \\
\hline
\end{tabular}

Jika dilihat table diatas maka dapat disimpulkan produk boardgame hootania sangat efektif dalam meniingkatkan budaya membaca pada anak usia 4 hingga 6 tahun. Aplikasi produk ini perlu didampingi oleh pengajar atau orang tua agar 
dapat menilai peserta didik yang sudah mahir membaca atau yang masih kurang. Penyebaran produk boardgame ini disebar ke taman kanak kanak di Kabupaten Bandung Barat dengan pemantauan perkembangan peserta didik dalam membaca.

\section{KESIMPULAN}

Board Game HOOTANIA yang dirancang untuk membantu anak dalam proses belajar membaca menggunakan konsep belajar sambil bermain. Untuk anak usia Taman Kanak-Kanak, belajar membaca merupakan hal yang sangat penting karena syarat untuk bisa melanjutkan ke jenjang selanjutnya. Sifat anak-anak tingkat TK yang masih senang dengan bermain, diharapkan Game ini bisa membuat anak-anak jadi lebih senang dalam belajar membaca karena konsepnya yang mengusung belajar sambil bermain.

\section{REFERENSI}

[1] Arum Nisma Wulanjani, \& Candradewi Wahyu Anggraeni. (2019). Meningkatkan Minat Membaca melalui Gerakan Literasi Membaca bagi Siswa Sekolah Dasar. Proceeding of Biology Education, 3(1), 26-31. https://doi.org/10.21009/pbe.3-1.4

[2] Sadiman, A. S. dk. (2009). Media Pendidikan. Al-Afkar : Jurnal Keislaman \& Peradaban, V(1), 5.

[3] Somantri, G. R. (2004). MEMAHAMI METODE KUALITATIF. Elektrosvyaz, 9(5), 26.

[4] Veronica, N. (2018). Permainan Edukatif Dan Perkembangan Kognitif Anak Usia Dini. Pedagogi : Jurnal Anak Usia Dini dan Pendidikan Anak Usia Dini, 4(2). https://doi.org/10.30651/pedagogi.v4i2.1939

[5] Wibayanti, R. dan S. H. (2019). Pentingnya Meningkatkan Minat Baca Siswa. Prosiding Seminar Nasional Pendidikan Program Pascasarjana Universitas Pgri Palembang, 767-775. www.perpusnas.go.id

[6] Wiratomo, Y. (2018). Analisis Kebutuhan pada Model pembelajaran Project Base Learning. Titian Ilmu: Jurnal Ilmiah Multi Sciences, 10(2). https://doi.org/10.30599/jti.v10i2.163

[7] Yuningsih, C. R. (2019). Pembelajaran Seni Rupa Di Pendidikan Anak Usia Dini. Jurnal Edukasi Sebelas April, 3(1). https://jurnal.stkip11april.ac.id/index.php/JESA/article/view/59

[8] Rahmania, S., Miarsyah, M., \& Sartono, N. (2015). The difference scientific literacy ability of student having field independent and field dependent cognitive style. Biosfer: Jurnal Pendidikan Biologi, 8(2), 27-34.

[9] Sulistyani, Anggraeni Mashinta. 2015. Pengenalan Sains bagi Anak Usia Dini Menggunakan Metode Permainan. Jurnal Insania: Jurnal Pendidikan. Fakultas Tarbiyah dan Ilmu Keguaran.Institut Agama Islam Negeri Purwokerto. Vol 20 No 1 Januari-Juni 2015 PP $13-27$

[10] Shofaussamawati. 2014. Menumbuhkan Minat Baca dengan Pengenalan Perpustakaan pada Anak Sejak Dini. Jurnal Libraria. STAIN Kudus. Vol 2 No 1 Th 2014

[11] Kartika Sony Dharsono.2016. Seni Rupa Modern. Rekayasa Sains. Bandung

[12] Sadiman, Arif S, Rahardjo, Anung Haryono, Rahardjito. (2009). Media Pendidikan Pengertian, Pengembangan, dan Peanfaatannya. Jakarta. Rajawali Pers. 